\title{
Effect of Salvia leriifolia Benth. root extracts on ischemia-reperfusion in rat skeletal muscle Hossein Hosseinzadeh*1, Azar Hosseini ${ }^{2}$, Marjan Nassiri-Asl ${ }^{3}$ and Hamid- Reza Sadeghnia 4
}

\author{
Address: ${ }^{1}$ Department of Pharmacology and Toxicology, Pharmaceutical Research Center, Faculty of Pharmacy, Mashhad University of Medical \\ Sciences, Mashhad, I.R. Iran, ${ }^{2}$ Faculty of Medicine, Mashhad University of Medical Sciences, Mashhad, I. R. Iran, ${ }^{3}$ Department of Pharmacology, \\ Faculty of Medicine, Qazvin University of Medical Sciences, Qazvin, I.R. Iran and ${ }^{4}$ Department of Pharmacology, School of Medicine, Mashhad \\ University of Medical Sciences, Mashhad, I.R. Iran \\ Email: Hossein Hosseinzadeh* - hosseinzadehh@mums.ac.ir; Azar Hosseini - schoolpharmacy@gmail.com; Marjan Nassiri- \\ Asl - marjan_nassiriaslm@yahoo.com; Hamid-Reza Sadeghnia - hsadeghnia@gmail.com \\ * Corresponding author
}

Published: 7 July 2007

BMC Complementary and Alternative Medicine 2007, 7:23 doi:10.1 186/1472-6882-7-23

This article is available from: http://www.biomedcentral.com/1472-6882/7/23

(C) 2007 Hosseinzadeh et al; licensee BioMed Central Ltd.

This is an Open Access article distributed under the terms of the Creative Commons Attribution License (http://creativecommons.org/licenses/by/2.0), which permits unrestricted use, distribution, and reproduction in any medium, provided the original work is properly cited.
Received: 9 August 2006

Accepted: 7 July 2007

\begin{abstract}
Background: Salvia leriifolia have been shown to decrease ischemia-reperfusion (I/R) injury in brain tissues. In this study, the effects of $S$. leriifolia aqueous and ethanolic extracts were evaluated on an animal model of I/R injury in the rat hind limb.

Methods: Ischemia was induced using free-flap surgery in skeletal muscle. The aqueous and ethanolic extracts of S. leriifolia $(100,200$ and $400 \mathrm{mg} / \mathrm{kg})$ root and normal saline $(10 \mathrm{ml} / \mathrm{kg})$ were administered intraperitoneally I $\mathrm{h}$ prior reperfusion. During preischemia, ischemia and reperfusion conditions the electromyographic (EMG) potentials in the muscles were recorded. The markers of oxidative stress including thiobarbituric acid reactive substances (TBARS), total sulfhydryl (SH) groups and antioxidant capacity of muscle (using FRAP assay) were measured.

Results: In peripheral ischemia, the average peak-to-peak amplitude during ischemic-reperfusion was found to be significantly larger in extracts groups in comparison with control group. Following extracts administration, the total $\mathrm{SH}$ contents and antioxidant capacity were elevated in muscle flap. The MDA level was also declined significantly in test groups.
\end{abstract}

Conclusion: It is concluded that S. leriifolia root extracts have some protective effects on different markers of oxidative damage in muscle tissue injury caused by lower limb ischemia-reperfusion.

\section{Background}

A vast amount of circumstantial evidence implicates oxygen-derived free radicals (especially superoxide and hydroxyl radical) and high-energy oxidants (such as peroxynitrite) are as mediators of inflammation, shock, and ischemia/reperfusion injury [1]. The oxidant injury can potentially occur during ischemia and reperfusion due to an excess production of oxygen free radicals, a decrease in antioxidant defenses, or both. Because antioxidants function by removing the toxic oxygen metabolites, they are generally highly effective in reducing ischemia-reperfusion injury [2]. Skeletal muscle ischemia and reperfusion injury remains an issue of concern because of the morbidity and mortality that follows revascularization of 
an acutely ischemic limb [3]. Many studies have suggested the beneficial antioxidant effects of antioxidant nutrients such as vitamin E, green tea extract, ginkgo biloba extract, resveratrol and niacin in cerebral ischemia and recirculation brain injury [4].

The plants of the genus Salvia, which consist about 900 species [5] are generally known for their multiple pharmacological effects such as analgesic and anti-inflammatory [6], antioxidant [7], hepatoprotective [8] and hypoglycemic activities [9]. Salvia leriifolia that was introduced in flora Iranica in 1982 [10] geographically grows in the south and tropical regions of Khorassan and Semnan provinces, I.R. Iran. In recent years, the different pharmacological activities of this plant such as the attenuation of morphine dependence [11], hypoglycemic [12], analgesic and anti-inflammatory [13,14], anticonvulsant [15], antiulcer effects [16] and antibacterial activities [17] were evaluated in our laboratory.

The anti-ischemia effects of some species of Salvia such as $S$. hematodes and $S$. miltiorrhiza $[18,19]$ have been reported. Our studies also showed the anti-ischemia effects of S. leriifolia extracts in hippocampus of rats [20]. Thus, in this study the effect of $S$. leriifolia extract was evaluated during ischemia-reperfusion on an animal model of $\mathrm{I} / \mathrm{R}$ injury in the rat hind limb.

\section{Methods}

\section{Animals}

Wistar male rats, 200-230 g were housed in colony rooms with $12 / 12 \mathrm{~h}$ light/dark cycle at $21 \pm 2{ }^{\circ} \mathrm{C}$ and had free access to food and water. All animal experiments were carried out in accordance with Mashhad University of Medical Sciences, Ethical Committee Acts.

\section{Chemicals}

TBA, n- butanol, phosphoric acid, potassium chloride and thiobarbituric acid were purchased from Merck. Xylazine and ketamine were obtained from Loughrea, Co. (Galway, Ireland) and Rotexmedica (GmbH, Germany), respectively. All chemical were dissolved in distilled water.

\section{Induction of ischemia}

The rats were anesthetized with intraperitoneal injection of ketamine/xylazine $(60 \mathrm{mg} / \mathrm{kg}$ and $6 \mathrm{mg} / \mathrm{kg}$, respectively). Additional doses of these agents were used if anesthesia lightened during experiment.

An incision in the inner side of the hind leg from the inguinal ligament to the tendon calcaneus insertion was made. Then it was divided up and the triceps surae was dissected as a muscle flap, after that insertions to femur was cut. Previously dissected femoral vessels, the artery and vein were clamped with a single clamp of microsur- gery. The absence of bleeding was verified in the muscle flap. Then the incision was closed to prevent desiccation. For reperfusion periods, the clamp of the femoral vessels of animals was taken off and then the bleeding of the muscle flap was verified. The muscle tissues was homogenized in cold $\mathrm{KCl}$ solution (1.5\%) to give a $10 \%$ homogeny suspension and used for biochemical assays. The results were expressed by $\mathrm{n}$ or $\mu \mathrm{M} / \mathrm{g}$ tissue $(1 \mathrm{ml}$ of homogenate $=0.1 \mathrm{~g}$ of tissue) [49].

Eight groups of animals were used, each of which contained 8 rats: Group 1 including sham operated animals, Group 2 served as ischemic control to which saline (10 $\mathrm{ml} / \mathrm{kg}$ ) was injected intraperitoneally (i.p.). Group 3-8 was received the aqueous and ethanolic extract (100, 200 and $400 \mathrm{mg} / \mathrm{kg}$ ). Except group 1, other groups underwent $2 \mathrm{~h}$ ischemia and $1 \mathrm{~h}$ reperfusion. All drugs were administrated $1 \mathrm{~h}$ before reperfusion.

\section{Electromyography data collection}

To determine the muscles activities during ischemiareperfusion, intramuscular electromyograph (EMG) signals were recorded with PowerLab data acquisition systems. Two pairs of pin electrodes in terminating alligator clips were inserted into the triceps surae (muscle flap) in hind leg, and adductor muscles. The distance between the two electrodes of a pair in each muscle was $5 \mathrm{~mm}$. A grounding electrode was gently attached to the rat tail [50]. The EMG signals were collected with sampling frequency of 12 PPM (MacLab/4SP). Duration for each stimulation was $20 \mathrm{~ms}$. The raw EMG signals were low-pass filtered at $50 \mathrm{~Hz}$ and EMG signal is expressed as average peak-to-peak amplitude for a $10 \mathrm{~min}$ recording periods. The electromyography (EMG) signals were recorded 10 min before ischemia, $10 \mathrm{~min}$ before reperfusion and 10 min at end of reperfusion phase.

\section{Preparation of Salvia leriifolia extracts}

S. leriifolia was collected from Bajestan (Razavi Khorasan province, Northeast of Iran) and authenticated by Pharmacognosy Department, School of Pharmacy, MUMS, Iran (Voucher No:153-1912-05). For preparation of aqueous extract, the powdered root (100 g) was boiled in 1000 $\mathrm{ml}$ boiling water for $15 \mathrm{~min}$. Subsequently, the mixture was filtered and concentrated under reduced pressure at $35^{\circ} \mathrm{C}$ (yield: $5.5 \% \mathrm{w} / \mathrm{w}$ ). As some constituents are sensitive to boiling water we also prepared a macerated extract. For preparation of the ethanolic extract, the powdered root $(100 \mathrm{~g})$ was macerated in $1000 \mathrm{ml}$ ethanol $(96 \% \mathrm{v} / \mathrm{v})$ for $72 \mathrm{~h}$ and subsequently the mixture was filtered and concentrated under reduced pressure at $35^{\circ} \mathrm{C}$ (yield: $6 \%$ $\mathrm{w} / \mathrm{w})$. 
A

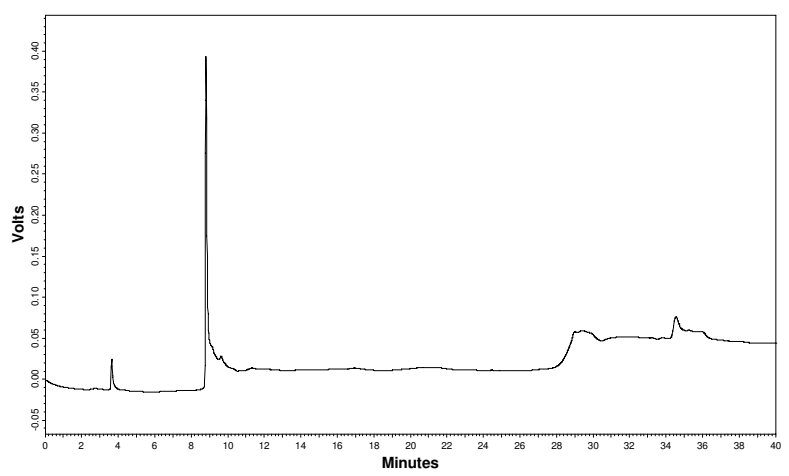

B

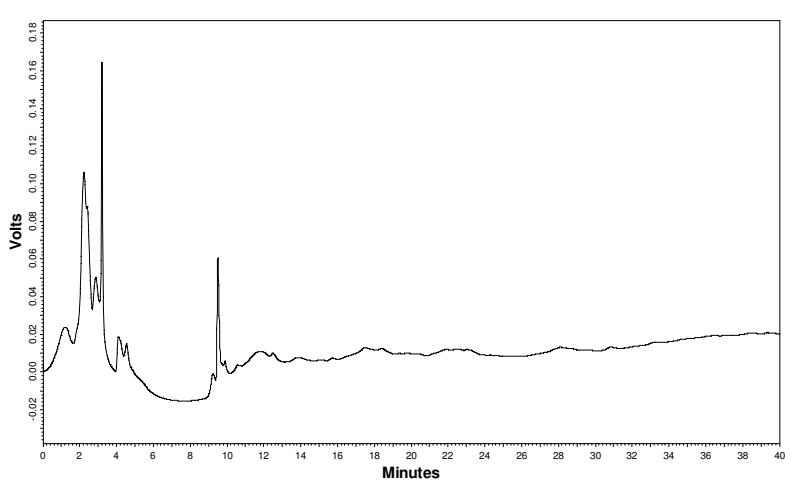

Figure I

HPLC fingerprint of the ethanolic (A) and aqueous (B) extracts of Salvia leriifolia root.

Preliminary chemical tests

Phytochemical screening of the extract was performed using the following reagents and chemicals (Trease and Evans, 1983): alkaloids with Dragendorff's reagent, flavonoids with the use of $\mathrm{Mg}$ and $\mathrm{HC1}$.; tannins with $1 \%$ gelatin and $10 \% \mathrm{NaCl}$ solutions and saponins with ability to produce suds and hemolysis reaction [51].

\section{Characterization of aqueous and ethanolic extracts by HPLC}

The quality of extracts of $S$. leriifolia radix was characterized by HPLC finger print. The aqueous and ethanolic extracts were dissolved in distilled water and acetonitrile respectively and then filtered through $0.22 \mu \mathrm{m}$ membrane filter. Twenty $\mu \mathrm{l}$ of sample $(10 \mathrm{~g} / \mathrm{l})$ was injected to the reverse phase column (C18). The mobile phase was consisted water: phosphoric acid 1N, 99:1 (as solvent A) and acetonitrile: phosphoric acid 1N, 99:1 (as solvent B) with a gradient elution $(0,95: 5 ; 5,92.5: 7.5 ; 10,90: 10 ; 15$, $87.5: 12.5 ; 20,85: 15 ; 25,82.5: 17.5 ; 30,80: 20 ; 35$,
$78.5: 22.5,40,75: 25)$ at the flow rate of $1 \mathrm{ml} /$ minute. The peaks were monitored at $236 \mathrm{~nm}$.

\section{Thiobarbituric acid reactive substances (TBARS) measurement}

Malondialdehyde (MDA) levels, as an index of lipid peroxidation, were measured. MDA reacts with thiobarbituric acid (TBA) as a thiobarbituric acid reactive substance (TBARS) to produce a red colored complex which has peak absorbance at $532 \mathrm{~nm}$ [52].

$3 \mathrm{ml}$ phosphoric acid (1\%) and $1 \mathrm{ml}$ TBA (0.6\%) was added to $0.5 \mathrm{ml}$ of homogenate in a centrifuge tube and the mixture was heated for $45 \mathrm{~min}$ in a boiling water bath. After cooling, $4 \mathrm{ml}$ of $\mathrm{n}$-butanol was added the mixture and vortex-mixed for $1 \mathrm{~min}$ followed by centrifugation at $20000 \mathrm{rpm}$ for $20 \mathrm{~min}$. The organic layer was transferred to a fresh tube and its absorbance was measured at 532 $\mathrm{nm}$. The standard curve of MDA was constructed over the concentration range of $0-40 \mu \mathrm{M}$ [53].

\section{Ferric Reducing/Antioxidant Power (FRAP) assay}

The FRAP assay measures the change in absorbance at 593 $\mathrm{nm}$ owing to the formation of a blue colored $\mathrm{Fe}^{2+}$-tripyridyltriazine compound from the colorless oxidized $\mathrm{Fe}^{3+}$ form by the action of electron donating antioxidants [54].

The FRAP reagent consist of $300 \mathrm{mM}$ acetate buffer $(3.1 \mathrm{~g}$ sodium acetate $+16 \mathrm{ml}$ glacial acetic acid, made up to 1 liter with distilled water; $\mathrm{pH}=3.6), 10 \mathrm{mM}$ TPTZ in 40 $\mathrm{mM} \mathrm{HCl}$ and $20 \mathrm{mM} \mathrm{FeCl}_{3} \cdot 6 \mathrm{H}_{2} \mathrm{O}$ in the ratio of $10: 1: 1$.

Briefly, $50 \mu \mathrm{l}$ of muscle homogenate was added to $1.5 \mathrm{ml}$ freshly prepared and prewarmed $\left(37^{\circ} \mathrm{C}\right)$ FRAP reagent in a test tube and incubated at $37^{\circ} \mathrm{C}$ for $10 \mathrm{~min}$. The absorbance of the blue colored complex was read against reagent blank ( $1.5 \mathrm{ml}$ FRAP reagent $+50 \mu$ distilled water $)$ at 593 $\mathrm{nm}$. Standard solutions of $\mathrm{Fe}^{2+}$ in the range of 100 to 1000 $\mathrm{mM}$ were prepared from ferrous sulphate $\left(\mathrm{FeSO}_{4} \cdot 7 \mathrm{H}_{2} \mathrm{O}\right)$ in distilled water. The data was expressed as $\mathrm{mM}$ ferric ions reduced to ferrous form per liter (FRAP value) [55].

\section{Total sulfhydryl (SH) groups assay}

Total SH groups were measured using DTNB (2, 2'-dinitro-5, 5'-dithiodibenzoic acid) as the reagent. This reagent reacts with the $\mathrm{SH}$ groups to produce a yellow colored complex which has a peak absorbance at $412 \mathrm{~nm}$ [56].

Briefly, $1 \mathrm{ml}$ Tris-EDTA buffer $(\mathrm{pH}=8.6)$ was added to 50 $\mu \mathrm{l}$ muscle homogenate in $2 \mathrm{ml}$ cuvettes and sample absorbance was read at $412 \mathrm{~nm}$ against Tris-EDTA buffer alone $\left(\mathrm{A}_{1}\right)$. Then $20 \mu \mathrm{l}$ DTNB reagent $(10 \mathrm{mM}$ in methanol) was added to the mixture and after $15 \mathrm{~min}$ (stored in laboratory temperature) the sample absorbance was read again $\left(A_{2}\right)$. The absorbance of DTNB reagent was also read 
Table I: Effects of Salvia leriifolia root aqueous and ethanolic extracts on average peak-to-peak amplitudes of EMG signals, prior, during and after ischemia-reperfusion in rat skeletal muscle.

\begin{tabular}{llll}
\hline Group $(\mathrm{n}=8)$ & Preischemia $(\mathrm{v})$ & Ischemia $(\mathrm{v})$ & Reperfusion $(\mathrm{v})$ \\
\hline Sham & $2.590 \pm 0.015$ & $2.671 \pm 0.018^{* * * *}$ & $2.588 \pm 0.033^{* * *}$ \\
Control group $(10 \mathrm{ml} / \mathrm{kg})$ & $2.800 \pm 0.044$ & $1.314 \pm 0.027$ & $1.495 \pm 0.025$ \\
Aqueous extract $100 \mathrm{mg} / \mathrm{kg}$ & $2.038 \pm 0.023$ & $2.110 \pm 0.030^{* * *}$ & $1.867 \pm 0.067^{* *}$ \\
Aqueous extract $200 \mathrm{mg} / \mathrm{kg}$ & $2.214 \pm 0.036$ & $2.296 \pm 0.016^{* * *}$ & $2.303 \pm 0.034^{* * *}$ \\
Aqueous extract $400 \mathrm{mg} / \mathrm{kg}$ & $2.440 \pm 0.030$ & $2.425 \pm 0.013^{* * *}$ & $2.112 \pm 0.025^{* * *}$ \\
Ethanolic extract $100 \mathrm{mg} / \mathrm{kg}$ & $2.040 \pm 0.027$ & $2.098 \pm 0.033^{* * *}$ & $1.846 \pm 0.075^{* *}$ \\
Ethanolic extract $200 \mathrm{mg} / \mathrm{kg}$ & $2.190 \pm 0.039$ & $2.291 \pm 0.019^{* * *}$ & $2.308 \pm 0.04 I^{* * *}$ \\
Ethanolic extract $400 \mathrm{mg} / \mathrm{kg}$ & $2.430 \pm 0.035$ & $2.422 \pm 0.014^{* * *}$ & $2.098 \pm 0.024^{* * *}$
\end{tabular}

Values are mean \pm S.E.M. $* * \mathrm{P}<0.0 \mathrm{I}$ and $* * * \mathrm{P}<0.00 \mathrm{I}$ when compared with control group with Tukey-Kramer test.

as a blank (B). Total thiol concentration (mM) was calculated from the following equation:

Total thiol concentration $(\mathrm{mM})=\left(\mathrm{A}_{2}-\mathrm{A}_{1}-\mathrm{B}\right) \times 1.07 / 0.05 \times$ 13.6

\section{Statistical analysis}

Data are expressed as mean \pm SEM. Statistical analysis was performed using one-way ANOVA followed by Tukey-

Sham
Control group (Saline $10 \mathrm{ml} / \mathrm{kg}$ )
$\square$ Aqueous Extract $100 \mathrm{mg} / \mathrm{kg}$
Aqueous Extract $200 \mathrm{mg} / \mathrm{kg}$
Aqueous Extract $400 \mathrm{mg} / \mathrm{kg}$

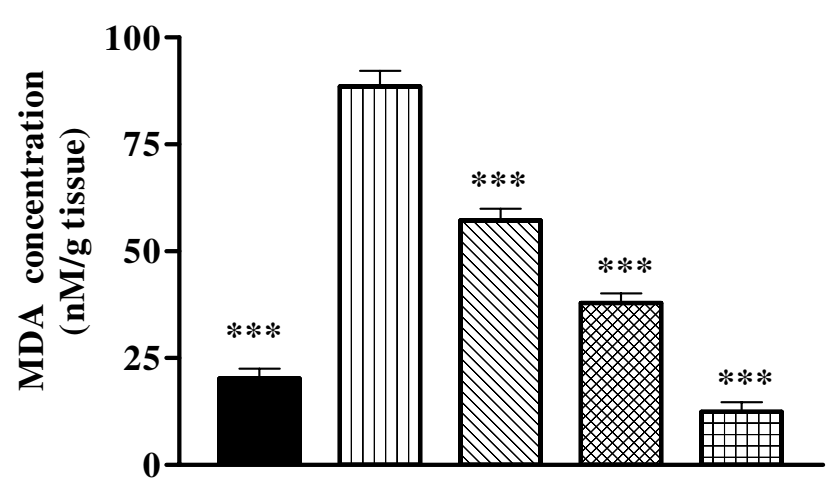

Figure 2

Effect of Salvia leriifolia root aqueous extract on lipid peroxidation following muscle ischemia reperfusion injury.MDA levels were measured in 10\% homogenates of muscle samples from rats subjected to $120 \mathrm{~min}$ of ischemia and $60 \mathrm{~min}$ of reperfusion. All drugs were administrated intraperitoneally 60 min prior to reperfusion. Values are mean $\pm \operatorname{SEM}(n=8)$. $*^{*} p<0.01$, ***p $<0.001$ as compared with vehicle (normal saline) treated animals (One-way ANOVA followed by Tukey-Kramer test)
Kramer post-hoc test for multiple comparisons. The p-values less than 0.05 were considered to be statistically significant.

\section{Results \\ Chemical analysis}

Preliminary phytochemical tests indicated that the aqueous and ethanolic extracts of S. leriifolia radix contain tannins and saponins. Alkaloids were found in low amount

Sham

$\square$ Control group (Saline $10 \mathrm{ml} / \mathrm{kg}$ )

Ethanolic Extract $100 \mathrm{mg} / \mathrm{kg}$

Ethanolic Extract $200 \mathrm{mg} / \mathrm{kg}$

Ethanolic Extract $400 \mathrm{mg} / \mathrm{kg}$

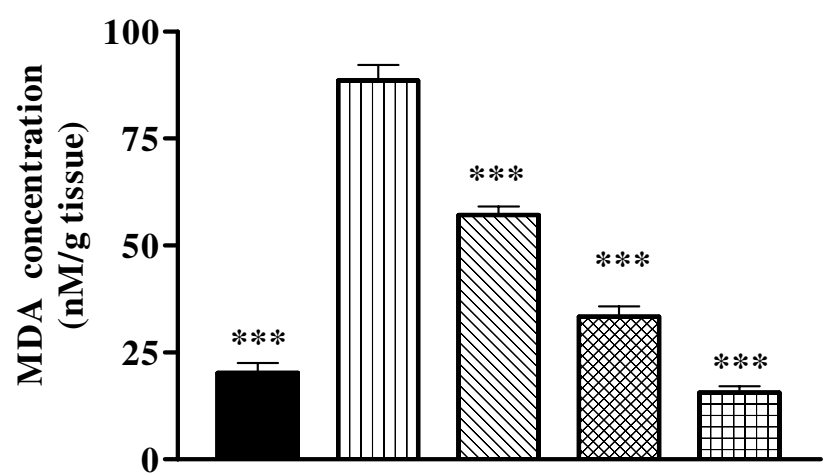

Figure 3

Effect of Salvia leriifolia root ethanolic extract on lipid peroxidation following muscle ischemia reperfusion injury. MDA levels were measured in $10 \%$ homogenates of muscle samples from rats subjected to $120 \mathrm{~min}$ of ischemia and $60 \mathrm{~min}$ of reperfusion. All drugs were administrated intraperitoneally 60 min prior to reperfusion. Values are mean \pm SEM $(n=8)$. $*^{*} p<0.0$ I, ***p $<0.00$ I as compared with vehicle (normal saline) treated animals (One-way ANOVA followed by Tukey-Kramer test) 


Sham
Control group (Saline $10 \mathrm{ml} / \mathrm{kg}$ )
Aqueous Extract $100 \mathrm{mg} / \mathrm{kg}$
Aqueous Extract $200 \mathrm{mg} / \mathrm{kg}$
Aqueous Extract $400 \mathrm{mg} / \mathrm{kg}$

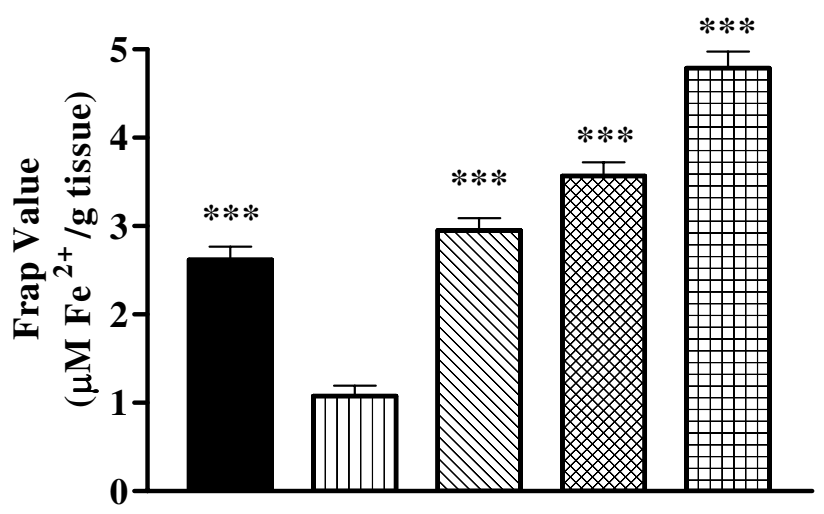

Figure 4

Effect of Salvia leriifolia root aqueous extract on antioxidant power of muscle homogenate samples following muscle ischemia reperfusion injury. FRAP values were measured in $10 \%$ homogenate samples from rats subjected to $120 \mathrm{~min}$ of ischemia and $60 \mathrm{~min}$ of reperfusion. All drugs were administrated intraperitoneally $60 \mathrm{~min}$ prior to reperfusion. Values are mean \pm SEM $(n=8)$. $* * * p<0.001$ as compared with vehicle (normal saline) treated animals (One-way ANOVA followed by Tukey-Kramer test)

in the ethanolic extract. HPLC fingerprints of aqueous and ethanolic extracts indicated a relatively different pattern. (Fig. 1A and 1B).

\section{Electromyography data}

The average peak-to-peak amplitudes in the controlischemic group and sham were $1.314 \pm 0.027,1.495 \pm$ $0.025 \mathrm{~V}$ and $2.671 \pm 0.018,2.588 \pm 0.033 \mathrm{~V}, \mathrm{p}<0.001$ ) respectively during ischemia and reperfusion. The aqueous and ethanolic extracts increased the amplitude compare with ischemia and reperfusion groups (Table 1).

Thiobarbituric acid reactive species (TBARS) measurement There was an increase in the MDA levels following ischemia reperfusion as compared with sham-operated animals $(20.18 \pm 3.65$ vs $88.53 \pm 3.65 \mathrm{nM} / \mathrm{g}$ tissue, $\mathrm{p}<$ 0.01 ) (Figure 2 and 3 ). The extracts pretreatment resulted in a significant reduction in the free radical-mediated lipid peroxidation as indicated by a decrease in the MDA levels, at various dose levels (Figures 2 and 3). A reduction in TBARS levels was very prominent in the higher doses.
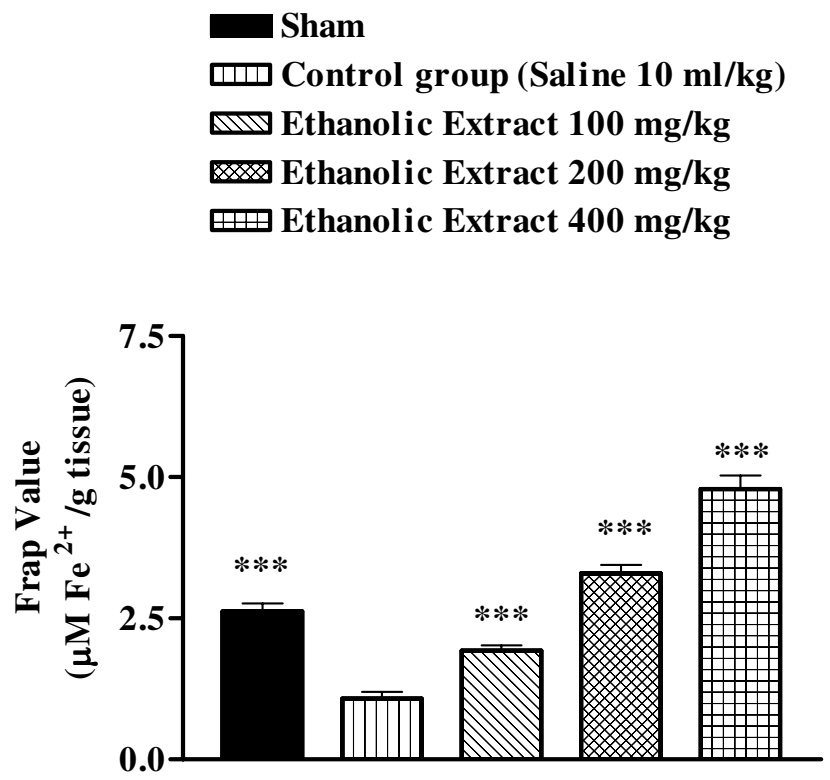

Figure 5

Effect of Salvia leriifolia root ethanolic extract on antioxidant power of muscle homogenate samples following muscle ischemia reperfusion injury. FRAP values were measured in $10 \%$ homogenate samples from rats subjected to $120 \mathrm{~min}$ of ischemia and $60 \mathrm{~min}$ of reperfusion. All drugs were administrated intraperitoneally 60 min prior to reperfusion. Values are mean \pm SEM $(n=8)$. **p $<0.01$, *** $p<0.001$ as compared with vehicle (normal saline) treated animals (One-way ANOVA followed by Tukey-Kramer test)

\section{Modulation of FRAP value}

Ischemia reperfusion caused a significant reduction in FRAP value of muscle homogenate samples as compared with sham-operated animals $(2.620 \pm 0.148$ vs. $1.076 \pm$ $0.119 \mu \mathrm{M} / \mathrm{g}$ tissue, $\mathrm{p}<0.001$ ) (Figure 4 and 5). The extracts pretreatment increased antioxidant power (FRAP value) of muscle homogenate samples (Figures 4 and 5).

\section{Total thiol concentration}

Following ischemia-reperfusion injury, a significant reduction in total $\mathrm{SH}$ groups $(0.728 \pm 0.027$ vs. $0.215 \pm$ $0.010 \mathrm{mM}, \mathrm{p}<0.001)$ in muscle homogenate samples was observed (Figure 7). The extracts pretreatment caused a significant elevation in total thiol concentration, as compared with control-ischemic group (Figures 6 and 7).

\section{Discussion}

The results obtained in the present investigation suggest that the S. leriifolia extracts have an overall protective effect against muscle I/R injury in a rat model.

A number of processes have been implicated in the pathogenesis of oxygen deprivation-induced cell injury. These 

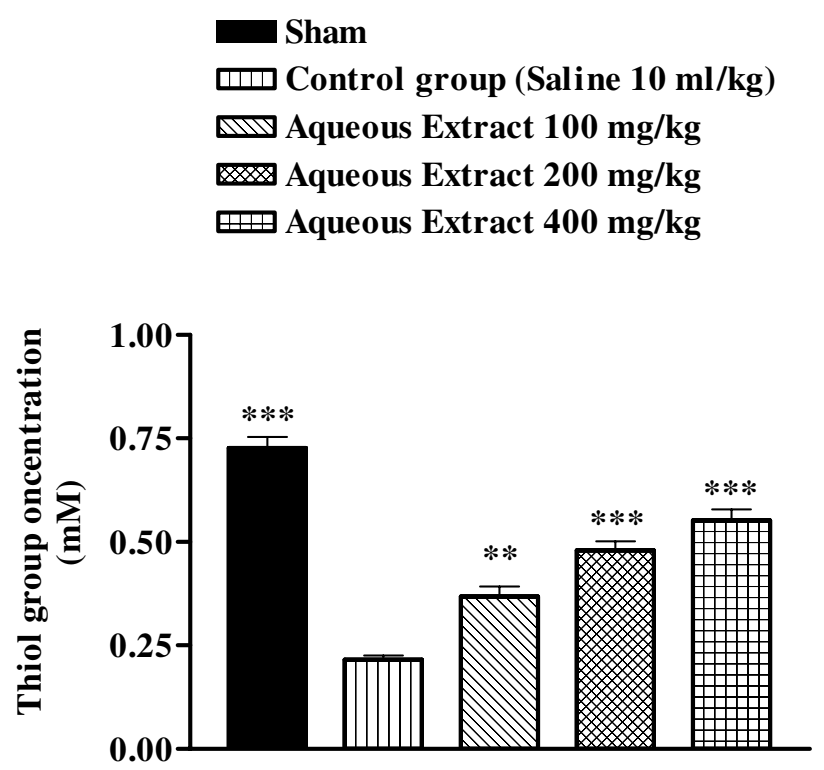

Figure 6

Effect of Salvia leriifolia root aqueous extract on total thiol concentrations following following muscle ischemia reperfusion injury. Total sulfhydryl ( $\mathrm{SH}$ ) groups were measured in $10 \%$ muscle homogenate samples from rats subjected to 120 min of ischemia and 60 min of reperfusion. All drugs were administrated intraperitoneally $60 \mathrm{~min}$ prior to reperfusion. Values are mean \pm SEM $(n=8)$. $* * * p<0.01$ as compared with vehicle (normal saline) treated animals (One-way ANOVA followed by Tukey-Kramer test).

include the disturbances of cell calcium homeostasis, depletion of adenine nucleotides, activation of enzymes like phospholipases with production of toxic lipid metabolites, proteases and endonucleases and generation of free radicals (ROS) that can cause oxidative damage to cellular macromolecules $[21,22]$. Antioxidant therapy has been well documented to help in the improvement of organ functions [23].

We assessed the effect of the S. leriifolia extracts studying their effects on lipid peroxidation, which was measured in terms of MDA, a stable metabolite of the free radicalmediated lipid peroxidation cascade. MDA levels increased significantly following muscle ischemia reperfusion. The S. leriifolia extracts reversed the increase of MDA levels to a considerable extent, thereby confirming its antioxidant role in $\mathrm{I} / \mathrm{R}$.

Sulfhydryl (SH) groups are highly-reactive constituents of protein molecules, and they participate in important biochemical and metabolic process such as cell division, blood coagulation, maintenance of protein systems and enzymatic activation including antioxidant enzymes (cat-
Sham
Control group (Saline $10 \mathrm{ml} / \mathrm{kg}$ )
Ethanolic Extract $100 \mathrm{mg} / \mathrm{kg}$
Ethanolic Extract $200 \mathrm{mg} / \mathrm{kg}$
Ethanolic Extract $400 \mathrm{mg} / \mathrm{kg}$

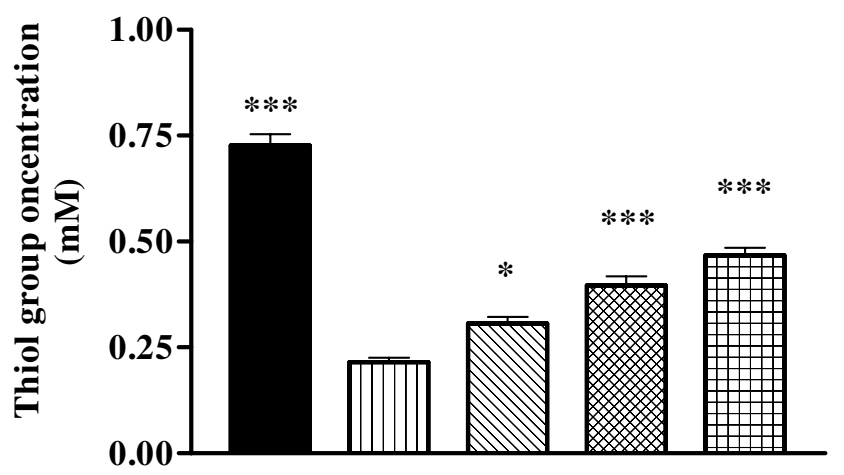

Figure 7

Effect of Salvia leriifolia root ethanolic extract on total thiol concentrations following muscle ischemia reperfusion injury. Total sulfhydryl $(\mathrm{SH})$ groups were measured in $10 \%$ muscle homogenate samples from rats subjected to $120 \mathrm{~min}$ of ischemia and $60 \mathrm{~min}$ of reperfusion. All drugs were administrated intraperitoneally $60 \mathrm{~min}$ prior to reperfusion. Values are mean $\pm \operatorname{SEM}(n=8)$. $*_{p}<0.05$, *** $p<0.01$ as compared with vehicle (normal saline) treated animals (One-way ANOVA followed by Tukey-Kramer test).

alase, superoxide dismutase, etc.) [24]. There are also important scavengers of oxygen-derived free radicals [25]. SH groups known to be sensitive to oxidative damage and depleted following ischemic insult [26], therefore we studied the effect of the aqueous and ethanolic extracts of $S$. leriifolia on total thiol concentration during muscle ischemia reperfusion. Similarly, in our studies, total sulfhydryl groups were decreased following I/R injury. These agents exhibited higher SH contents than their respective controls, indicating that helped in replenishing the total thiol pool.

Under acute and chronic pathologic conditions such as ischemia, the balance between oxidant and antioxidant systems has been interrupted $[27,28]$. Therefore we evaluate the antioxidant or reducing potential of muscle homogenate samples following muscle ischemia reperfusion, using FRAP assay. As expected following this, a significant reduction in antioxidant power, as indicated by FRAP value, was observed. The aqueous and ethanolic extracts increased the antioxidant power of muscle homogenate samples. 
The S. leriifolia extracts showed anti-ischemia activity in this study. Phytochemical test showed that the extracts comprised saponins and tannins. Antihypoxic and antiischemic activities of some of these components such as protopanaxatriol and ginsenosides have been reported [29-31]. Monoterpenes as the one of the constituents of the essential oil of $S$. leriifolia showed good antioxidant activity [32]. There are several reports about the antioxidant activity and anti-inflammatory effects of some monoterpenoids such as $\alpha$-pinene. Moreover, there have been shown monoterpenoids such as terpineol and linalool have depressant effects on central nervous system, in vivo [32] and linalool competitively inhibits glutamate receptors [33]. However, the chemical constituents responsible for the pharmacological activities of the extracts remain to be investigated. Phytochemical assays and HPLC finger prints showed a little difference between these two extracts but it seems this variation does not affect on anti-ischemia effects. The maximum effect was shown with higher doses of both extracts

It seems that ischemia reperfusion injury reduced the conductivity and viability of muscles and nerves. In this study, the S. leriifolia extracts maintained the nerve conductivity. Nerve conduction is decreased during ischemia-reperfusion [34,35]. Mild muscle necrotic changes occur after $2-3 \mathrm{~h}$ ischemia $[36,37]$. Oxidative stress and the production of oxygen free radicals during ischemia-reperfusion is one mechanism of ischemic fiber degeneration, causing a breakdown of the blood-nerve barrier, endoneurial edema and lipid peroxidation [38]. S. leriifolia extracts prevented lipid peroxidation and showed antioxidant activity in this study. These effects and other activities such as anti-inflammatory effect $[13,14]$ may preserve viability of nerve conductivity.

Present study showed that $S$. lerrifolia extracts suppressed the increase of MDA levels in the rat skeletal muscle and therefore inhibited lipid peroxidation following ischemia-reperfusion injury. The inhibition of lipid peroxidation and anti-ischemic effects are probably related to the antioxidant properties and free radical scavengering of the S. leriifolia extracts.

A number of study have shown that the other species of Salvia genus, especially $S$. miltiorrihiza, possess antioxidant activities $[7,39]$, vasodilatory effects $[40]$, the inhibition of nitric oxide production [41], glutamate release [42] and elevation of ATP levels (and probably adenosine) in brain [43].

Several studies have demonstrate that adenosine and its analogues possess antihypoxic, anti-ischemic [44-46] and neuromodulatory properties [47] and prevent lipid peroxidation following ischemia-reperfusion episodes [48]. It may be possible that adenosine had a role in the antiischemic effects of the extracts. However, this hypothesis needs to be more investigated.

\section{Conclusion}

The results of this study showed the aqueous and the ethanolic extracts of $S$. leriifolia radix had protective effects against muscle ischemic injury and significantly decreased the lipid peroxide level in rat muscle following peripheral ischemia- reperfusion damages. The present study showed S. leriifolia extracts have protective effect on ischemia reperfusion injury-induced oxidative stress in rats muscle that at least partly due to antioxidant properties of S. leriifolia extract.

\section{References}

I. Cuzzocrea S, Riley DP, Caputi AP, Salvemini D: Antioxidant therapy : a new pharmacological approach in shock, inflammation, and ischemia/reperfusion injury. Pharmacol Rev 200I, 53:135-159.

2. Das DK, Maulik N: Antioxidant effectiveness in ischemiareperfusion tissue injury. Methods Enzymol 1994, 233:60I-6I0.

3. Ascher E, Hanson JN, Cheng W, Hingorani A, Scheinman M: Glycine preserves function and decreases necrosis in skeletal muscle undergoing ischemia and reperfusion injury. Surgery 200I, 129:23|-235.

4. Ikeda $\mathrm{K}$, Negishi $\mathrm{H}$, Yamori $\mathrm{Y}$ : Antioxidant nutrients and hypoxia/ischemia brain injury in rodents. Toxicology 2003, 189:55-6I.

5. Brickell C: "Encyclopedia of Garden Plants" London: Dorling Kindersley; 1996:926.

6. Hernandez-Perez M, Rabanal RM, de la Torre MC, Rodriguez B: Analgesic, anti-inflammatory, antipyretic and haematological effect of aethiopinone, an o-naphthoquinone diterpenoid from Salvia aethiopis roots and two hemisynthetic derivatives. Planta Med 1995, 61:505-509.

7. Cuppett SL, Hall CA: Antioxidant activity of the Labiatae. Adv Food Nutr Res 1998, 42:245-27I.

8. Wasser S, Ho JM, Ang HK, Tan CE: Salvia miltiorrhiza reduce experimentally-induced hepatic fibrosis in rats. J Hepatol 1998 , 29:760-77।.

9. Jimenez J, Risco S, Ruiz T, Zarzuelo A: Hypoglycemic activity of Salvia lavandulifolia. Planta Med 1996, 4(52):260-262.

10. Rechinger $\mathrm{KH}$ : "Flora Iranica". Graz-Austeria: Akademische Druck-U. Verlagsantalt 1982:439-440.

11. Hosseinzadeh H, Lari P: Effect of Salvia leriifolia extract on morphine dependence in mice. Phytother Res 2000, 14:384-387.

12. Hosseinzadeh H, Haddadkhodaparast MH, Shokoohizadeh H: Antihyperglycemic effect of Salvia leriifolia Benth. leaf and seed extract in mice. Irn J Med Sci 1998, 23:74-80.

13. Hosseinzadeh H, Yavari M: Anti-inflammatory effects of Salvia leriifolia Benth. leaf extract in mice and rats. Pharmac Pharmacol Lett 1999, 9:60-61.

14. Hosseinzadeh H, Haddadkhodaparast MH, Arash A: Antinociceptive, anti-inflammatory and acute toxicity effects of Salvia leriifolia Benth. seed extract in mice and rats. Phytotherapy Res 2003, 17:422-425.

15. Hosseinzadeh H, Arabsanavi J: Anticonvulsant effect of Salvia leriifolia Benth. seed and leaf extracts in mice. Irn J Basic Med Sci 200I, 3:166-170.

16. Hosseinzadeh $\mathrm{H}$, Haddadkhodaparast $\mathrm{MH}$, Hosseini E: Anti-ulcer effect of Salvia leriifolia Benth. leaf extracts in mice. Pharmac Pharmacol Lett 2000, 2:63-64.

17. Habibi Z, Eftekhar F, Samiee K, Rustaiyan A: Structure and antibacterial activity ofp6 new labdane diterpenoid from Salvia leriaefolia. I Nat Prod 2000, 63:270-27I.

18. Akbar S, Tariq M, Nisa M: A study on CNS depressant activity of Salvia haematodes wall. Int J Crude Drug Res 1984, 22:41-44.

19. Yu WG: Effect of acetylsalvianolic acid $\mathbf{A}$ on platelet function. Yao Xao Xue 1994, 29:412-416. 
20. Sadeghnia HR, Nassiri Asl M, HaddadKhodaparast MH, Hosseinzdeh $\mathrm{H}$ : The effect of Salvia leriifolia Benth. Root extracts on lipid peroxidation level during global ischemic-reperfusion in rats. J Med Plants 2003, 7:19-28.

21. Rhodena E, Teloken C, Lucas M, Rhoden C, Mauri M, Zettler C, BelloKleind A, Barros E: Protective effect of allopurinol in the renal ischemia-reperfusion in uninephrectomized rats. General Pharmacol 2002, 35:189-93.

22. Montagna G, Hofer CG, Torres AM: Impairment of cellular redox status and membrane protein activities in kidneys from rats with ischemic acute renal failure. Biochem Biophys Acta 1998, 1407:99-108.

23. Lee JY, Lott JA, Kauffman EM, Sharma HM: Effect of herbal mixture MAK-4 on organ functions in WHHL rabbits. Biochem Arch 1997, I 3:285-296.

24. Jansen EV: Sulfhydryl-disulfide interchanges. Science 1959, 130:1319-23.

25. Dormandy TL: An approach to free radicals in medicine and biology. Acta Physiol Scand 1980, 492: I 53-68.

26. Soszynski M, Bartosz G: Decrease in accessible thiols as an index of oxidative damage to membrane proteins. Free Rad Biol Med 1980, 23:463-469.

27. Abdollahi M, Ranjbar R, Shadnia S, Nikfar S, Rezaie A: Pesticides and oxidative stress: a review. Med Sci Monit 2004, I O(RA): |4|-47.

28. Parihar MS, Hemnani T: Phenolic antioxidants attenuate hippocampal neuronal cell damage against kainic acid induced excitotoxicity. J Biosci 2003, 28: I2I-28.

29. Dou DQ, Zhang YW, Zhang L, Chen YJ, Yao X-S: The inhibitory effects of ginsenosides on protein tyrosine kinase activated by hypoxia/reoxygenation in cultured human umbilical vein endothelial cells. Planta Med 2001, 67:19-23.

30. Sui DY, Lu ZZ, Ma LN: Effects of the leaves of Acanthopanax senticosus on myocardial infarct size were studied in acute ischemic dogs. Chung Kuo Xao Tsa Chin 1994, 19:746-747.

31. Wen TC, Yoshimura H, Matsuda S, Lim JH, Sakanaka M: Ginseng root prevents learning disability and neuronal loss in gerbils with minute fore brain ischemia. Acta Neuropathol 1996 91:15-22.

32. Perry NSL, Bollen C, Perry EK, Ballard C: Salvia for dementia therapy: review of pharmacological activity and pilot tolerability clinical trial. Pharmacol Biochem Behav 2003, 75:65I-659.

33. Silva Brum LF, Elisabetsky E, Souza D: Effect of linalool on ${ }^{3} \mathbf{H}$ ] $\mathrm{MK80I}$ and $\left[{ }^{3} \mathrm{H}\right]$ muscimol binding in mouse cortical membranes. Phytother Res 200I, 1 5:422-425.

34. Oguzhanoglu A, Kurt T, Sahiner T: Nerve conduction parameters during ischemia-reperfusion in the rat sciatic nerve. Electromyogr Clin Neurophysiol 2000, 40:487-490.

35. Schmelzer JD, Zochodne DW, Low PA: Ischemic and reperfusion injury of rat peripheral nerve. Proc Natl Acad Sci USA 1989, 86:1639-1642.

36. Korthals JK, Maki T, Gieron MA: Nerve and muscle vulnerability to ischemia. J Neurol Sci 1985, 71:283-290.

37. lida H, Schmelzer JD, Schmeichel AM, Wang Y, Low PA: Peripheral nerve ischemia: reperfusion injury and fiber regeneration. Exp Neurol 2003, I 84:997-1002.

38. Nagamatsu M, Schmelzer JD, Zollman PJ, Smithson IL, Nickander KK, Low PA: Ischemic reperfusion causes lipid peroxidation and fiber degeneration. Muscle Nerve 1996, 19:37-47.

39. Wang T: Effects of Chinese medicine zhenxianling in $\mathbf{2 3 9}$ case of epilepsy. J Tradit Chin Med 1996, 16:94-97.

40. Masahiro N: Vasodilator effects of des ( $\alpha$-carboxy-3, 4-dihydroxy phenethyllithospermic acid $\beta$-epilechnic acid-, a derivative of lithospermic acids in Salvia miltiorrhiza radix. Biol Pharmac Bull 1996, 19:228-232.

41. Kuang P: Effect of radix Salvia miltiorrhizae on nitric oxide in cerebral ischemia-eperfusion injury. J Tradit Chin Med 1996 1 6:224-227.

42. Kuang P: Effect of radix Salvia miltiorrhizae on EAA and IAA during cerebral ischemia in gerbil: a microdialysis study. Tradit Chin Med 1994, I 4:45-50.

43. Wang SX, Xie SH: Effect of ATP quantity of myocardium and brain in mice by extract from Rubia yannanensis, Rubia corliifolia and Salvia miltiorrhiza. Chin Trad Herbal Drugs 1986, I 7:45 I-453.
44. Laghi PF, Guideri F, Dicano E, Parenti G, Varga A, Diperri T: Increase in plasma adenosine during brain ischemic attacks and stroke. Brain Res Bull 2000, 5 I:327-330.

45. Mori M, Nishizaki T, Okada Y: Protective effect of adenosine on the anoxic damage of hippocampal slice. Neuroscience 1992, 46:301-307.

46. Nieber K, Eschke D, Brand A: Brain hypoxia: effects of ATP and adenosine. Prog Brain Res 1999, I 20:287-297.

47. Hosseinzadeh $\mathrm{H}$, Stone TW: Adenosine in the central nervous system. Med J Isl Rep Iran 1996, 9:36I-368.

48. Yavuz O, Turkozkan N, Bilgihan A, Dogulu F, Aykol S: The effect of 2- chloroadenosine on lipid peroxide level during experimental cerebral ischemia-reperfusion in gerbils. Free Rad Biol Med 1997, 22:337-34|.

49. Hosseinzadeh $H$, Nassiri Asl $M$, Parvardeh $S$ : The effects of carbenoxolone, a semisynthetic derivative of glycyrrhizinic acid, on peripheral and central ischemia-reperfusion injuries in the skeletal muscle and hippocampus of rats. Phytomedicine 2005, 1 2:632-637.

50. Ossowska K, Lorence-Koci E, Schulze G, Wolfarth S: The influence of dizolcipine (MK-80I) on the reserpine-enhanced electromyographic stretch reflex in rats. Neurosci Lett 1996, 203:73-76.

5I. Trease GE, Evans WC: Pharmacognosy. London: Bailliere Tindall Press; 1983:309-706.

52. Fernandez J, Perez-Alvarez JA, Fernandez-lopez JA: Thiobarbituric acid test for monitoring lipid oxidation in meat. Food Chem 1997, 99:345-353.

53. Uchiama M, Miahara M: Determination of malonaldehyde precursor in tissues by thiobarbituric acid test. Anal Biochem 1978 86:279-286.

54. Benzie IFF, Strain J]: The ferric reducing ability of plasma (FRAP) as a measure of antioxidant power: The FRAP assay. Anal Biochem 1996, 239:70-76.

55. Benzie IFF, Strain J]: Ferric reducing/antioxidant power assay: direct measure of total antioxidant activity of biological fluids and modified version for simultaneous measurement of total antioxidant power and ascorbic acid concentration. Methods Enzymol 1999, 299:15-27.

56. Ellman G: Tissue sulfhydryl groups. Arch Biochem Biophys 1959 , 82:70-77.

\section{Pre-publication history}

The pre-publication history for this paper can be accessed here:

http://www.biomedcentral.com/1472-6882/7/23/prepub
Publish with Biomed Central and every scientist can read your work free of charge

"BioMed Central will be the most significant development for disseminating the results of biomedical research in our lifetime. "

Sir Paul Nurse, Cancer Research UK

Your research papers will be:

- available free of charge to the entire biomedical community

- peer reviewed and published immediately upon acceptance

- cited in PubMed and archived on PubMed Central

- yours - you keep the copyright

Submit your manuscript here:

http://www.biomedcentral.com/info/publishing_adv.asp
BioMedcentral 